Institutional Sign In

Browse

My Settings

Get Help

Subscribe
Advertisement

Conferences > 2018 13th Iberian Conference...

\title{
Dependence in self-care with comorbidity, indicators of nursing care and contributions to an ontology of aging: Systematic review of the literature
}

8 Author(s) Cesar Fonseca ; Antonio Lista ; Manuel Lopes ; Felismina Mendes ; PhD ... View All Authors

28

Full
Text Views

Abstract

Metrics

More Like This

\section{Export to}

Allabratec

Manage

Content Alerts

Add to Citation

Alerts

PDF

Abstract: Background: Rehabilitation Nursing assumes a fundamental role in contemporary society in the response to the installation of new paradigms of chronic illness and dependen... View more

Metadata
Advertisement

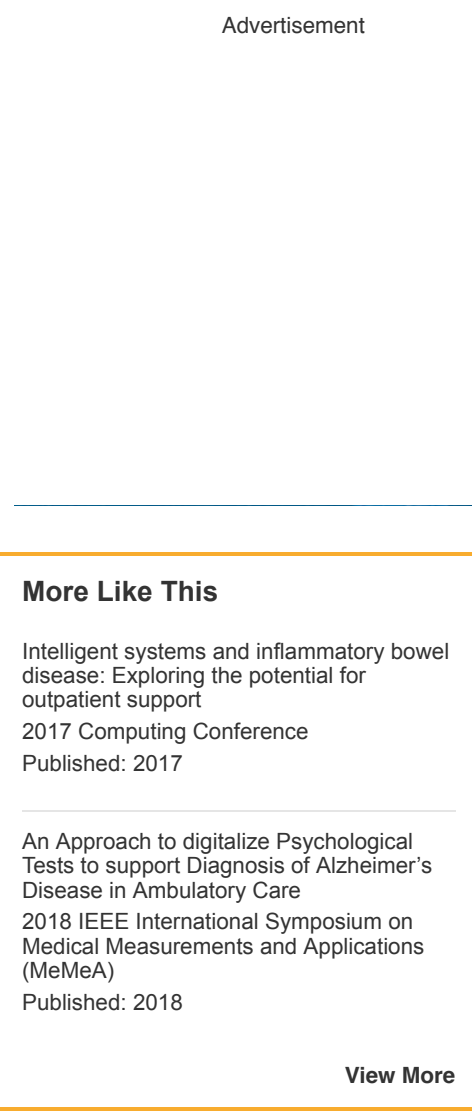

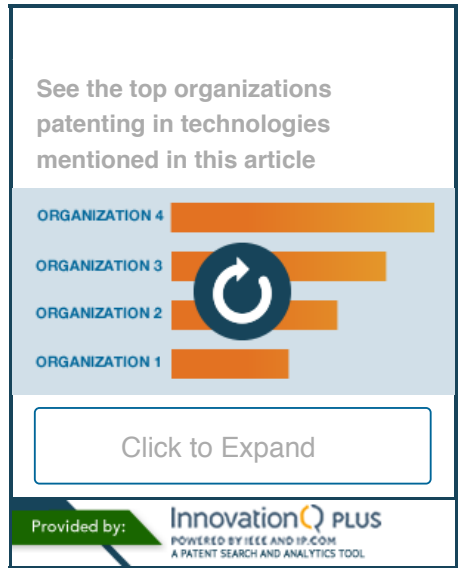


Abstract:

Background: Rehabilitation Nursing assumes a fundamental role in contemporary society in the response to the installation of new paradigms of chronic illness and dependence, induced by demographic aging and the advent of a large number of associated comorbidities. Health indicators sensitive to Rehabilitation Nursing care reflect how these nurses contribute to the health of the population in order to achieve health gains. It is necessary to define and contribute to the ontology of aging, which will allow, using machine learning processes, to provide foundations for knowledge acquisition and support for professional decision-making. Objective: To determine the indicators to be included in the ontology of aging, in relation to nursing care of rehabilitation of dependent elderly people in self-care with various comorbidities. Methods: A systematic review of the literature was carried out. Articles published between 2012 and 2017 were selected by searching the MEDLINE, CINAHL and MedicLatina database, using PI [C] OS methodology, resulting in the selection of 11 articles. Results: We identified 30 sensitive indicators of Rehabilitation Nursing care in relation to the dependent person in self-care with comorbidity. As a proposal for inclusion in the ontology of aging. From the qualitative synthesis of the indicators, improvements were observed in the variables: Readaptation and Functional Reeducation; Wellness and Self Care; Symptom Control; Prevention of Complications; REFEhregaifordofypport; Customer Satisfaction; Use of Health Services; Quality of Life; Promotion of Social Inclusion; Self-management of Disease and Health Promotion.

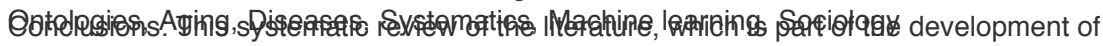
an ontology of aging and its integration into the discipline of Rehabilitation Nursing, aims

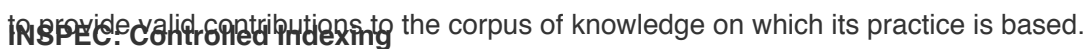
The recognition of indicators sensitive to rehabilitation nursing care is an opportunity for

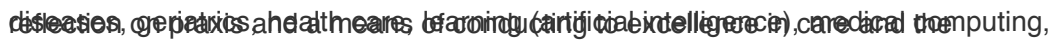

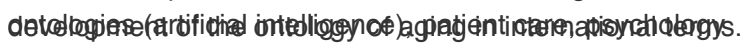

\section{(View less)}

INSPEC: Non-Controlled Indexing

Published in: 2018 13th Iberian Conference on Information Systems and Technologies gerseripidity, demographic aging, Health indicators, rehabilitation nursing care,

Self Care, elderly people, ontology, machine learning

Date of Conference: 13-16 June 2018

INSPEC Accession Number: 17879654

Author Keywords

Date Added to IEEE Xplore: 28 June 2018DOI: 10.23919/CISTI.2018.8399236

Rehabilitation Nursing, Self-Care, Functionality, Comorbidity, Health Indicators,

ontSBgylnformation: Publisher: IEEE

Conference Location: Caceres, Spain

\begin{tabular}{ll}
\hline & \\
\hline Authors & $\vee$ \\
\hline Keywords & $\wedge$
\end{tabular}

\section{IEEE Keywords}

Ontologies, Aging, Diseases, Systematics, Machine learning, Sociology

\section{INSPEC: Controlled Indexing}

diseases, geriatrics, health care, learning (artificial intelligence),

medical computing, ontologies (artificial intelligence), patient care, psychology

\section{INSPEC: Non-Controlled Indexing}

comorbidity, demographic aging, Health indicators, rehabilitation nursing care,

Self Care, elderly people, ontology, machine learning

\section{Author Keywords}

Rehabilitation Nursing, Self-Care, Functionality, Comorbidity, Health Indicators, 
ontology

Metrics

$\checkmark$

IEEE Account

Profile Information

Purchase Details

Need Help?

Other

A not-for-profit organization, IEEE is the world's largest technical professional organization dedicated to advancing technology for the benefit of humanity.

(c) Copyright 2019 IEEE - All rights reserved. Use of this web site signifies your agreement to the terms and conditions.

US \& Canada: +18006784333

Worldwide: +17329810060

IEEE Account

"Change Username/Password

" Update Address

\section{Purchase Details}

"Payment Options

»Order History

"View Purchased Documents

\section{Profile Information}

"Communications Preferences

"Profession and Education

"Technical Interests

\section{Need Help?}

" US \& Canada: +1 8006784333

» Worldwide: +1 7329810060

"Contact \& Support

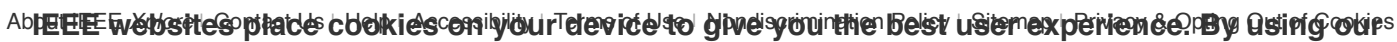

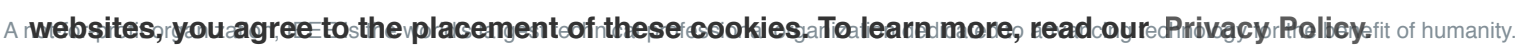

Accept \& Close

๑ Copyright 2019 IEEE - All rights reserved. Use of this web site signifies your agreement to the terms and conditions. 